23. Sn can be present to $0.4 \%$ by weight in disseminated form in chalcopyrite, a Cu-Fe sulfide and the most common source of copper metal in Mexico.

24. We consider an artifact to be made from an alloy when the concentration of the alloying element is sufficient to alter the working properties of the metal. In the case of As, that is $\geq 0.5 \%$; for $\mathrm{Sn}$, it is $\geq 1 \%$.

25. The bells made from $\mathrm{Cu}$ tend to be smooth walled (Fig. 4; nos. 1 and 2); the bronze bells (Cu-As and $\mathrm{Cu}-\mathrm{Sn}$ ) are wirework types. This particular relation between metal or alloy and design attributes also holds for West Mexican bells and has been shown to result from the mechanical requirements of these designs: The increased fluidity and strength that the alloys provide optimize the design of the thin, intricate, wirework forms.

26. Intermediate 1 and intermediate 2 were studied previously by D. M. K. de Grinberg, R. E. Rubinovich, and A. A. Gasca [Metalurgia de America Precolombina (Banco de La República, Bogotá, Columbia, 1986), pp. 37-65] also using an electron microbeam microanalyzer. The results differ in that we detected As and $\mathrm{Fe}$ in both samples: Grinberg et al.'s results show both to be absent in intermediate 1 . The difference could possibly reflect segregation in the material or the number of points that were analyzed in the section; we analyzed 37 points in the matrix metal; Grinberg et al. analyzed five.

27. See geological maps for $\mathrm{Cu}$ and $\mathrm{Sn}$ deposits produced by the Instituto de Geología, Universidad Nacional Autónoma de México (UNAM) Two Sn deposits are shown in the State of San Luis Potosi; $\mathrm{Cu}$ deposits occur in the states of Tamaulipas and San Luis Potosi. Arsenopyrite occurs in San Luis Potosi at the deposits of Catorce and Guadalcázar (W. Panczner, Minerals of Mexico (Van Nostrand Reinhold, New York 1987)

28. C. L. Diaz Oyarzabal, Colección de Objetos de Piedra, Obsidiana, Concha Metales y Textiles de Estado de Guerrero (Col. Catálogo de Museos INAH, Mexico City, Mexico, 1990); D. Hosler, unpublished data.

29. G. Stresser-Pean, unpublished data.

30. See M. Smith [Anc. Mesoam. 1, 153 (1990)] for an extended discussion of late Post Classic longdistance trade of Aztec goods, particularly of ceramic and obsidian.

31. D. Michelet, Rio Verde San Luis Potosi (Mexique) (CEMCA, Mexico, 1984); W. Jimenez Moreno, E Norte de México y el sur de Estados Unidos (Tercera Reunión de Mesa Redonda, Sociedad Mexicana de Antropología, Mexico, 1943)

32. M. Smith, personal communication.

33. The Aztec tribute province of Oxitipa appears in the Codex Mendoza [F. Berdan and P. Anawalt The Codex Mendoza (Univ. of California-Berkeley, 1992)], but the codex does not mention the villages included in the province.

34. The study and sampling were carried out under a permit granted by the Instituto Nacional de Antropologia e Historia in Mexico City. The authors gratefully acknowledge INAH's support. The French Archaeological Mission carried out the excavations, directed by G. Stresser-Pean. D. Hosler performed the laboratory analytic studies at the Massachusetts Institute of Technology. F Leipziger performed the atomic absorption studies. We also thank $L$. Compton and the Undergraduate Research Opportunities Program (UROP) at MIT for funding her work.

\title{
Protein Oxidation and Aging
}

\author{
Earl R. Stadtman
}

A number of systems that generate oxygen free radicals catalyze the oxidative modification of proteins. Such modifications mark enzymes for degradation by cytosolic neutral alkaline proteases. Protein oxidation contributes to the pool of damaged enzymes, which increases in size during aging and in various pathological states. The age-related increase in amounts of oxidized protein may reflect the age-dependent accumulation of unrepaired DNA damage that, in a random manner, affects the concentrations or activities of numerous factors that govern the rates of protein oxidation and the degradation of oxidized protein.

Thirty-six years ago, Harmon (1) suggested that free radicals are likely involved in the aging process. In the meantime, the free radical theory of aging has become widely accepted and is the basis of numerous hypotheses to explain how free radicals might be involved. Nevertheless, the relevance of free radicals in aging is clouded by diverse opinions as to what aging really is. Some hold that aging is a programmed phase of cellular differentiation and normal development that culminates in death. Others believe that aging is the manifestation of progressive losses in physical and mental acuity caused by the impairment of fundamental physiological processes by illdefined factors. So far as the radical theory is concerned, distinction between these

The author is Chief of the Laboratory of Biochemistry, National Heart, Lung, and Blood Institute, National Institutes of Health, Bethesda, MD 20892. concepts is blurred by a growing body of evidence that free radical damage to cellular function is associated with a number of age-related diseases-namely, atherosclerosis, arthritis, muscular dystrophy, cataractogenesis, pulmonary dysfunction, various neurological disorders, and very likely cancer (2). This notwithstanding, few would question the importance of free radical damage to nucleic acids and lipids in agerelated disease processes. From measurements of the in vivo production of modified purine and pyrimidine bases, presumed to arise from the excision and repair of damaged nucleic acid, Ames et al. (3) have reasoned that oxygen free radicals are responsible for 10,000 or so DNA base modifications per cell per day. It requires little persuasion to accept the argument that a finite fraction of such a massive amount of damage would escape repair by even the most sophisticated mechanisms and that the accumulation of unrepaired damage could account for the age-related loss of physiological function. There is little reluctance to accept the view that oxygen free radical-mediated lipid peroxidation could lead to the loss of membrane integrity and hence compromise cellular function. Accordingly, much attention has been given to the potential roles of free radical damage to nucleic acids and lipids in aging. Curiously, until recently, the possibility that free radical damage to proteins might also contribute to aging has received less attention. This lack of interest may be a result in part of a failure to demonstrate age-related defects in the protein synthetic machinery or in the in vivo production of oxidatively damaged protein (4). In addition, it seemed reasonable that damaged protein would not accumulate because cellular proteins arE constantly turning over and that abnormal 5 ly formed or damaged proteins turn over more rapidly than normal proteins.

It was, in fact, an effort to understand how cells regulate the turnover of individ ual enzymes that led to the work summa? rized here, which shows that metal cata-을 lyzed oxidation (MCO) of enzymes is के marking step in protein turnover and that the accumulation of oxidized protein is likely implicated in aging.

\section{Two-Step Mechanism of Enzyme Degradation}

The rates of synthesis and degradation of somes enzymes are dependent on nutritional factors $E$ In Escherichia coli and Klebsiella aerogenes, glu은 tamine synthetase (GS) and several othero enzymes are rapidly degraded under conditions of nitrogen starvation (5-7). Subse quently, it was determined that the degrada tion of GS involves two steps (6). In the firs step, the enzyme is oxidized to a catalyticallo inactive form, which in the second step is rapidly degraded by intracellular proteases. The first step involves the oxidation of amino acid residues of the enzyme by the combined action of $\mathrm{H}_{2} \mathrm{O}_{2}$ and $\mathrm{Fe}^{2+}$ (Fig. 1). In the case of some amino acids, this leads to the formation of carbonyl derivatives.

The production of $\mathrm{H}_{2} \mathrm{O}_{2}$ and $\mathrm{Fe}^{2+}$ is catalyzed by any one of several different enzyme systems that are variously referred to as mixedfunction oxidation systems (8) or MCO systems (9). These systems include a large class of flavoproteins, reduced forms of nicotinamide adenine dinucleotide phosphate [NAD(P)H] oxidases, the reduced form of nicotinamide adenine dinucleotide quinone reductase, dehydrogenases, and cytochrome $\mathrm{P}-450$ reductases, which in intermediary metabolism normally serve as electron carriers between various metabolic reactions. However, under conditions of oxidative stress or in 
the absence of an appropriate electron acceptor, the reduced forms of these flavoproteins may react with $\mathrm{O}_{2}$ to form $\mathrm{H}_{2} \mathrm{O}_{2}$ or with $\mathrm{Fe}^{3+}$ to form $\mathrm{Fe}^{2+}$ by either superoxide anion radical $\left(\mathrm{O}_{2}^{--}\right)$-dependent or $\mathrm{O}_{2}^{-}$-independent pathways (2). Nonenzymic MCO systems comprised of ascorbate- $\mathrm{Fe}^{3+}-\mathrm{O}_{2}$ or $\mathrm{RSH}-\mathrm{O}_{2-}$ $\mathrm{Fe}^{3+}$ are also able to generate $\mathrm{H}_{2} \mathrm{O}_{2}$ and $\mathrm{Fe}^{2+}$. Because these mimic important characteristics of the enzymic MCO systems, they have been widely used in mechanistic studies $(6,10-12)$.

\section{The Site-Specific Nature of Metal-Catalyzed Reactions}

The only function attributed to MCO systems is the generation of $\mathrm{H}_{2} \mathrm{O}_{2}$ and $\mathrm{Fe}^{2+}$ (Fig. 1). The available evidence suggests that these products react in a site-specific manner to modify amino acid residues at the metal binding sites of proteins (Fig. 2).

In this mechanism, it is assumed that the hydroxyl radical $(\cdot \mathrm{OH})$ is the reactive oxygen species formed by the reaction of $\mathrm{Fe}$ (II) with $\mathrm{H}_{2} \mathrm{O}_{2}$. However, other active forms of oxygen (ferryl ion, perferryl ion, peroxyradical) may also be formed. The important consideration is that the reaction is viewed as a caged process in which the active oxygen species is not released into the surrounding medium but preferentially reacts

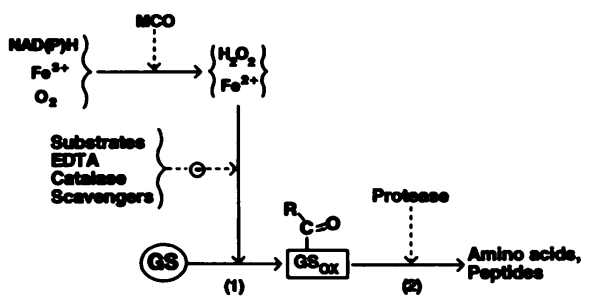

Fig. 1. Two-step mechanism of enzyme degradation. GS, glutamine synthetase; $\mathrm{GS}_{\mathrm{Ox}}$, oxidized glutamine synthetase. with functional groups of amino acid residues at the metal binding site. This would account for the observations that the MCO-catalyzed reactions are not inhibited by free radical scavengers $(8,10,13)$ and that only one or a few amino acid residues of a given enzyme subunit are modified by MCO systems. The mechanism is also supported by other observations. (i) All MCO systems that catalyze the oxidative modification of enzymes are able to catalyze the reduction of $\mathrm{O}_{2}$ to $\mathrm{H}_{2} \mathrm{O}_{2}$ and of $\mathrm{Fe}$ (III) to $\mathrm{Fe}$ (II) (8). (ii) $\mathrm{A}$ mixture of $\mathrm{H}_{2} \mathrm{O}_{2}$ and $\mathrm{Fe}$ (II), but not of $\mathrm{H}_{2} \mathrm{O}_{2}$ and $\mathrm{Fe}$ (III), will promote oxidative inactivation of enzymes (8). (iii) Catalase inhibits modification of enzymes by all of the MCO systems examined $(2,6,8,10)$. (iv) Iron chelators (EDTA, $o$-phenanthroline) inhibit the inactivation of all enzymes tested except creatine kinase (6, 8) and glucose-6-phosphate dehydrogenase (G6PDH). Chelators actually stimulate the oxidation of the latter two enzymes, presumably because they possess a binding site for the Fe-chelate complex.

The site-specific nature of the metal-catalyzed reactions has been confirmed by the results of studies with $E$. coli GS, which show that inactivation of the enzyme involves the conversion of $\mathrm{His}^{269}$ to an Asn (11) and of $\mathrm{Arg}^{344}$ to a glutamic semialdehyde derivative (12). Moreover, these His and Arg residues are both situated at one of the two metal binding sites at the catalytic center of the enzyme (14). Susceptibility of the enzyme to degradation by the multicatalytic protease is associated with the modification also of a second His residue ( $\mathrm{His}^{209}$ or $\mathrm{His}^{210}$ ) (15), which is situated at the second metal binding site on the enzyme (14).

\section{Protein Modification}

All amino acid residues of a protein are subject to attack by hydroxyl radicals pro-

Flg. 2. Site-specific mechanism of protein oxidation by MCO systems. The MCO system catalyzes the reduction of $\mathrm{Fe}$ (III) to $\mathrm{Fe}$ (II) (reaction 1) and the reduction of $\mathrm{O}_{2}$ to $\mathrm{H}_{2} \mathrm{O}_{2}$ (reaction 2). The $\epsilon$ amino group of a lysyl residue $\left(-\mathrm{CH}_{2} \mathrm{NH}_{2}\right)$ serves as one of several ligands to which $\mathrm{Fe}$ (II) binds (reaction 3). Oxidation of the protein-bound $\mathrm{Fe}$ (II) by $\mathrm{H}_{2} \mathrm{O}_{2}$ leads to the production of $\cdot \mathrm{OH}$ and $\mathrm{OH}^{-}$ (reaction 4). The $\mathrm{OH}$ abstracts a hydrogen atom from the $-\mathrm{CH}_{2} \mathrm{NH}_{2}$ carbon atom to form an alkyl radical (reaction 5). Transfer of the lone electron of the alkyl radical to $\mathrm{Fe}$ (III) in the complex

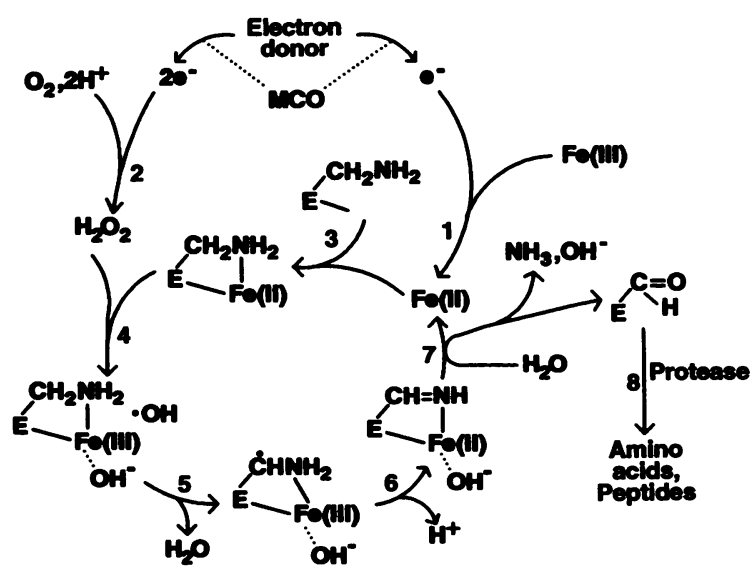

leads to the regeneration of $\mathrm{Fe}$ (II) and the formation of an imino derivative of the $\epsilon$ amino group (reaction 6). Spontaneous hydrolysis of the imino group leads to the release of the $\mathrm{Fe}(\mathrm{II})$ and the generation of an aldehyde derivative of the lysyl side chain (reaction 7). Finally, the modified protein is degraded by intracellular proteases (reaction 8). E, enzyme. duced by ionizing radiation; however, Tyr, Phe, Trp, His, Met, and Cys residues are the preferred targets $(16,17)$. These same amino acids are preferentially oxidized when proteins are exposed to ozone (18). Moreover, under anaerobic conditions, radiolytically generated radicals promote considerable protein-protein cross-linking through $\cdot \mathrm{OH}$-facilitated $-\mathrm{S}-\mathrm{S}$ - and - TyrTyr-bonding, whereas in the presence of $\mathrm{O}_{2}$, radiolysis leads to considerable fragmentation of the polypeptide chain, probably by the peroxyradical-mediated $\alpha$ amidation pathway $(16,17,19,20)$.

This pathway leads to cleavage of the $\alpha$ carbon-nitrogen bond of some amino acid residues to form two peptide fragments (reaction 1):

\section{RCONHC( $\left.\mathrm{R}^{\prime}\right) \mathrm{HCONHR}^{\prime \prime} \rightarrow$ \\ $\mathrm{RCONH}_{2}+\mathrm{R}^{\prime} \mathrm{COCNHR}$}

One fragment contains a $\mathrm{COOH}$-terminal ${ }^{-}$ amide group; the $\mathrm{NH}_{2}$-terminal residue of $\mathrm{N}$ the other fragment is blocked by an $\alpha \stackrel{\sim}{N}$ ketoacyl group.

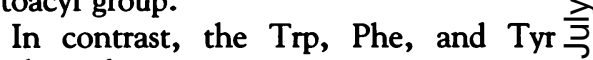
residues of proteins are not common targets for iron-catalyzed reactions, perhaps be- 0 cause these residues are not generally locat- $\overline{0}$ ed at metal binding sites. Some of these amino acid residues (Pro, Arg, and Lys) that are particularly sensitive to oxidation by MCO systems (Table 1 ) are converted to carbonyl derivatives.

\section{The Relationship Between Protein Oxidation and Protein Degradation}

The proposition that oxygen radical-mediated oxidation of enzymes is a marking step 0 in protein turnover $(5-7)$ is confirmed by several observations. (i) Many common proteases degrade oxidized proteins more rapidly than unoxidized forms (21-24). (ii) Many, perhaps all, animal tissues contain a neutral alkaline protease (the multicatalytic proteinase) that degrades the oxidized forms of enzymes but has little or no ability to degrade their unoxidized counterparts $(22$, 24). (iii) The in vivo degradation of endogenous proteins in liver and heart mitochondria and red blood cells is greatly stimulated by exposure of the cells to oxygen radical generating systems or $\mathrm{H}_{2} \mathrm{O}_{2}$ (25). (iv) The exposure of pure enzymes or proteins to oxygen free radicals in vitro increases their susceptibility to degradation by adenosine 5 -triphosphate-independent proteases in extracts of $E$. coli, liver, and heart mitochondria and red blood cells $(17,26)$.

\section{The Relationship Between Protein Oxidation and Aging}

Catalytically inactive or not very active, more heat-labile forms of some enzymes 
accumulate during aging (27). Because many of these enzymes are highly sensitive to modification by MCO systems, it was proposed that the age-related changes of some enzymes are a result of oxygen free radical-mediated damage $(5,28)$ and that the accumulation of damaged protein is a result of an age-related increase in the rate of oxygen free radical-mediated damage or a loss in the ability to degrade oxidized proteins $(28,29)$. Both propositions have gained experimental support.

With the finding that some amino acid residues are oxidized to carbonyl derivatives (Table 1 and reaction 1), it became evident that the carbonyl content of proteins could be used as one measure of protein damage. Therefore, several highly sensitive procedures were developed for the detection and quantitation of protein carbonyl groups (29). By means of these techniques, it was established that there is a small but significant increase in the amount of oxidized protein (carbonyl content) as a function of cell age in human erythrocytes (30) as well as in several other aging models. Thus, the carbonyl content of proteins in cultured human dermal fibroblasts increases expo-

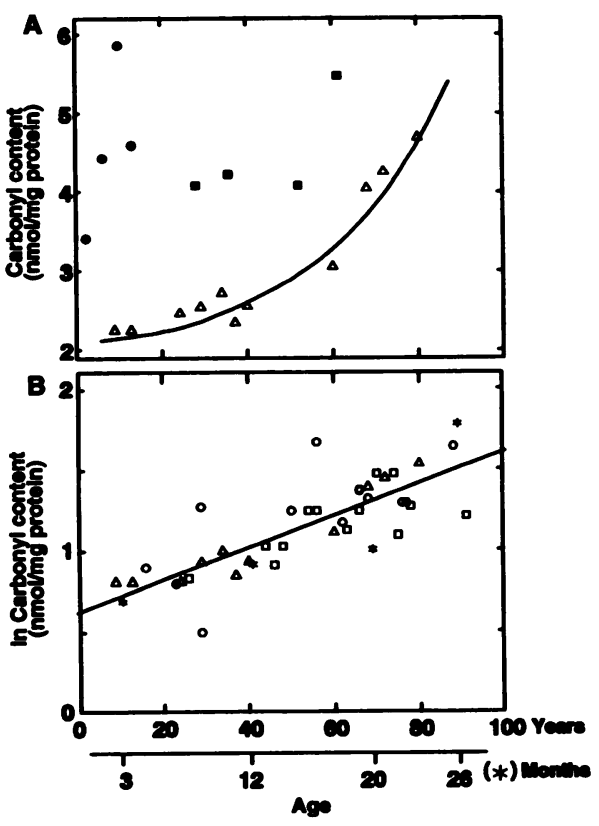

Fig. 3. Age-related changes in the amounts of oxidized protein. (A) Carbonyl content of cultured human dermal fibroblasts from normal individuals $(\Delta)$, from patients with progeria $(\theta)$, and from patients with Werner's syndrome ( $\square$ ). Adapted from Oliver et al. (30). (B) Semilog plot of the carbonyl content of proteins versus age for cultured dermal fibroblasts from normal individuals $(\Delta)$ [data from $(A)$ ], from the occipital lobe of human brain tissue (O) (31), from the human eye lens cortex ( $\square$ ) (32), and from rat liver hepatocytes (asterisks) (33). The scale from 0 to 26 months refers to data for rat liver hepatocytes. The scale from 0 to 100 years is for data from human samples. nentially with respect to the age of the fibroblast donor (Fig. 3). Moreover, the carbonyl content of cultured fibroblasts from individuals with premature aging diseases (progeria and Werner's syndrome) is very much higher than that in fibroblasts of age-matched normal individuals (30). In fact, amounts of protein carbonyl in patients with premature aging diseases are about the same as those found in fibroblasts of 80-year-old normal individuals (Fig. 3). A linear relationship between the logarithm of the carbonyl content of proteins in cultured fibroblasts from normal individuals and the age of the fibroblast donor (Fig. 3B) attests to the exponential nature of the age-dependent change.

A similar relationship exists between subject age and the amount of protein carbonyl groups in the occipital pole of the human brain (31), in the human eye lens cortex (32), and in rat hepatocytes (33) (Fig. 3). In all four systems, the amount of carbonyl groups varied from about $2 \mathrm{nmol}$ per milligram of protein in the youngest subject to 3.5 to $4.5 \mathrm{nmol}$ per milligram of protein in the oldest subject. Even greater changes were found in the frontal lobe of the human brain (31). At first glance, a two- to threefold age-related increase in the amount of protein carbonyl groups may not seem impressive. However, it has been estimated (33) that $2 \mathrm{nmol}$ of carbonyl groups per milligram of protein, an amount commonly found in young individuals, represents damage to about $10 \%$ of the total cellular protein. Accordingly, oxidized protein in old individuals could amount to 20 to $30 \%$ of the total cellular protein. These are minimal values, as the oxidative modification of some amino acid residues in protein does not lead to carbonyl derivatives (Table 1). Carbonyl groups are not formed in the conversion of His to Asp, of Pro to hydroxyproline or glutamate, of Cys to disulfide derivatives, or of Met to methionine sulfoxide. Realistically, 40 to $50 \%$ of the protein in old individuals might be present in an oxidatively damaged form. This estimate is in line with observations that the amounts of GS and G6PDH in rat liver hepatocytes (33) and gerbil brain (34) of old animals are only 40 to $60 \%$ of the amounts found in young animals and that the amounts of GS and creatine kinase in the human brain in old individuals are only 50 to $55 \%$ of the amounts found in young individuals (31).

\section{Age-Related Changes in Neutral Alkaline Protease Activity}

The age-related increase in oxidized protein in rat liver hepatocytes and in the gerbil or human brain is accompanied by a progressive decrease in the amount of neutral alkaline protease activity $(31,33,34)$. There is, in fact, an inverse linear relation between the amount of catalytically inactive forms of GS and G6PDH that accumulate in rat hepatocytes during aging and the amount of neutral alkaline protease $(2,33)$. This raises the possibility that the accumulation of damaged protein in older individuals is a result of a loss in the ability to degrade it.

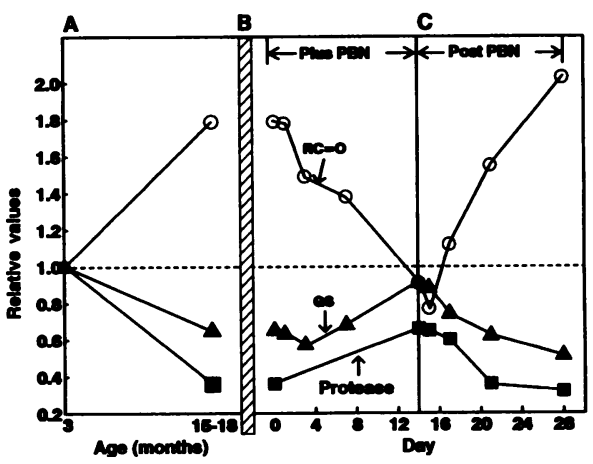

Fig. 4. Effect of age and PBN treatment on amounts of oxidized protein, GS activity, and $\bar{D}$ neutral alkaline protease activity of the gerbil brain. (A) Comparison of 3-month-old and 15to 18-month-old gerbil brains. (B) Changes during chronic treatment (twice daily injections, $35 \mathrm{mg}$ per kilogram of body weight) with PBN. (C) Changes after PBN treatment was discontinued. Replot of data from Carney et al. (34). The values of each parameter measured in the brains of old gerbils (15 to 18 months old) were normalized to the corresponding values observed with young gerbils ( 3 months old) that were arbitrarily set at a value of 1.0 , as indicated by the dashed line. Oxidized protein (O); GS $(\boldsymbol{\Delta})$; neutral protease ( $\square$ ).

Table 1. Amino acid residues of protein that are oxidized by MCO systems.

\begin{tabular}{clc}
\hline Residue modified & \multicolumn{1}{c}{ Product formed } & References \\
\hline Proline & $\begin{array}{l}\text { Glutamic semialdehyde; glutamate; } \\
\text { cis-trans-4-hydroxyproline }\end{array}$ & $(45)$ \\
& Glutamic semialdehyde & $(46)$ \\
Arginine & 2-Aminoadipicsemialdehyde & $(12,45)$ \\
Lysine & Asparagine-aspartate & $(47)$ \\
Histidine & Methionine sulfoxide & $(11)$ \\
Methionine & Tyr-Tyr cross-links & $(16,20)$ \\
Tyrosine & $-S-S-$ cross-links; mixed disulfides & $(16,48)$ \\
Cysteine & S & $(16,20)$ \\
\hline
\end{tabular}

SCIENCE • VOL. $257 \bullet 28$ AUGUST 1992 


\section{Reversal of Some Age-Related Changes}

Oliver et al. (35) showed that the free radical-mediated tissue damage and protein oxidation that occurs during ischemia and reperfusion of Mongolian gerbil brains could be partially prevented by pretreatment of the animals with radical spin trap tert-butyl- $\alpha$-phenylnitrone (PBN). In subsequent studies, Carney et al. (34) demonstrated that PBN can also influence agerelated changes in the gerbil brain. The amount of oxidized protein in the brains of old (15- to 18-month-old) gerbils is about 1.8 times that found in young (3-monthold) animals, whereas the amounts of GS and neutral protease activities in old animals were only 60 and $34 \%$, respectively, of the amounts in young animals (Fig. 4). These age-related changes were accompanied by an appreciable loss of temporal and spatial memory, as measured by the radialarm maze test (36). Chronic treatment of an old animal with PBN led to a progressive decrease in the amount of oxidized protein in its brain and to an increase in the amounts of GS and protease activities. After 14 days of treatment, the amounts of all three parameters as well as the extent of memory acuity were similar to those found in young animals (34). However, when the PBN treatment was discontinued, the values of all three biochemical parameters changed and after 14 days without PBN were similar to those found in old animals. The use of PBN in these studies was prompted by the consideration that it would serve as a free radical trap. However, not discounted is the possibility that PBN owes it effects to the pharmacological action of a metabolically derived productone whose mode of action is unrelated to free radical chemistry.

\section{The Physiological Significance of Oxidized Protein Accumulation}

A remarkable feature of living organisms is the ability to regulate their metabolism such that the rate of biodegradative and biosynthetic processes can be continuously varied to meet changes in biological urgency. This is achieved by means of highly sophisticated mechanisms for the regulation of both the activities and the amounts of key enzymes in metabolism. Therefore, substantial decreases in the amounts of important enzymes and the accumulation of massive amounts of damaged protein as occurs during aging seriously compromise cellular integrity. Carney et al. (34) showed that the age-related spatial and temporal memory in old gerbils can be reversed by chronic treatment of old animals with PBN. This indicates linkage between the age-related accumulation of damaged protein and the loss of an important physiological function.

\section{The Origin of Protein Carbonyl Groups}

Some amino acid residues are converted to carbonyl derivatives by active oxygen species produced by ionizing radiation, by MCO systems (Table 1), and by ozone. That oxygen free radicals are implicated in the production of protein carbonyl derivatives in vivo is indicated by the results of studies showing that the amounts of protein carbonyl groups in rat hepatocytes increase nearly 3.3-fold when rats are exposed to $100 \%$ oxygen for a period of 48 hours (37) and also by the demonstration that there is a significant increase in the protein carbonyl content of the gerbil brain during ischemia and reperfusion (35). Nevertheless, direct oxidation of amino acid side chains is not the only way that carbonyl groups can be introduced into protein (Fig. 5). Glycation involves the interaction of reducing sugars with the $\epsilon$ amino group of Lys residues to form Schiff bases, which undergo Amidori rearrangement to form ketoamines (38). Alternatively, the sugar can be oxidized to form a ketoaldehyde derivative that can react with Lys residues to produce a Schiff base derivative possessing a carbonyl function (39). These glycation products react further to yield highly fluorescent brown pigments of unknown structure (Maillard products) whose concentrations increase with the age of the animal (40). It is not known whether Maillard products contribute significantly to the pool of protein carbonyl groups.

Esterbauer and co-workers $(41,42)$ have shown that the free radical-mediated oxidation of polyunsaturated fatty acids leads to the production of $\boldsymbol{\alpha}, \boldsymbol{\beta}$-unsaturated aldehydes, especially 4-hydroxynonenal; these may react with the sulfhydryl groups of proteins, through a Michael addition type of mechanism, to form stable thioether derivatives that possess a carbonyl function (Fig. 5) (42). In the course of efforts to develop procedures for the detection and quantitation of such protein thioether adducts (43), it was discovered that $\alpha, \beta$ unsaturated aldehydes undergo facile reactions with His and Lys residues, probably by means of Michael addition reactions (Fig. 5 ), to form adducts that possess carbonyl groups. Highly sensitive assay procedures for the quantitation of Michael-type adducts of 4-hydroxynonenal with His, Cys, and Lys residues of proteins have been developed (44). By means of these procedures, it was determined that the Michael addition reaction accounts for less than $10 \%$ of the age-related increase in protein carbonyl content of rat hepatocytes (44). It remains to be determined whether glycation contributes significantly to the agerelated increase in protein carbonyl content.

\section{The Molecular Basis of Oxidized Protein Accumulation}

The age-related increase in the amount of oxidized protein can be explained by either an age-dependent increase in the rate of protein oxidation or a decrease in the ability to degrade oxidized protein. An increase in the rate of protein oxidation could reflect changes in any one of a large number of factors: (i) an increase in the rate of $\mathrm{O}_{2}$ delivery to cells, as might occur by changes in the amounts of allosteric effectors that govern the binding affinity of hemoglobin for $\mathrm{O}_{2}$; (ii) a deficiency in the transfer of $\varepsilon$ electrons that favors the build-up of reduced flavoproteins that then undergo auto- $\tau$ oxidation to form $\mathrm{H}_{2} \mathrm{O}_{2}$; (iii) an increase in 8 the availability of $\mathrm{Fe}$ (II) or $\mathrm{Cu}$ (II) by changes in the efficacy of metal binding proteins and chelating agents; (iv) depletion of the reduced glutathione amount that would restrict the ability of glutathione peroxidase to scavenge $\mathrm{H}_{2} \mathrm{O}_{2}$ and alkyl peroxides; $(\mathrm{v})$ a decrease in the amount of
Fig. 5. Generation of protein carbonyl groups by glycation and reactions with $\alpha, \beta$-unsaturated aldehydes. $\mathrm{P}-\mathrm{NH}_{2}, \in$ amino group of Lys residues of proteins; P-SH, cysteinyl sulfhydryl groups of proteins; P-His, histidyl residues of proteins; PUFA, polyunsaturated fatty acids; "O $\mathrm{O}_{2}$," activated oxygen species.

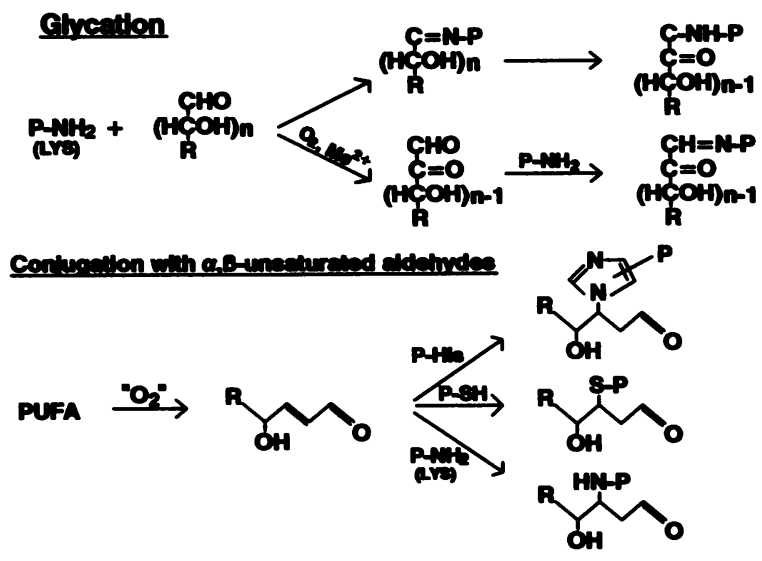
(n) , 
active oxygen scavengers (superoxide dismutase, catalase, glutathione peroxidase, bilirubin, vitamin E, carotenoids, uric acid; and (vi) changes in the concentrations of substrates that protect enzymes from oxidative modification. A decrease in the ability to degrade oxidized proteins could reflect changes in the amounts or activities of the proteases that degrade oxidized proteins or in the concentrations of metabolites that inhibit protease activities. The importance of the protease activity is highlighted by the fact that the accumulation of oxidized protein varies inversely with the amount of neutral alkaline protein activity and especially by the observation of Carney et al. (34) that chronic treatment of old gerbils with $\mathrm{PBN}$ resulted in an increase in the neutral protease activity in their brains and coincidentally led to a reversal of several age-related changes, including the restoration of temporal and spatial memory function and of oxidized protein amounts to amounts similar to those found in young animals.

It is of particular interest, however, that when the treatment of old gerbils with PBN was discontinued, the values of all parameters tested reverted to those characteristic of the old animal before PBN treatment. Thus, the PBN therapy could overcome some manifestations of old age, but it was unable to effect permanent reversal of the disorders, which indicates that genetic changes may be responsible for these manifestations. This observation and the results of earlier studies showing that the amount of oxidized protein in cultured human fibroblasts varies with the age of the fibroblast donor and is independent of the cell passage number, at least over the intermediate range of passages (30), suggest that the intracellular amount of oxidized protein is genetically specified and is a fairly stable phenotypic characteristic of cells. The progressive increase in the amount of oxidized protein with age might be explained by the accumulation of oxygen free radical damage that leads one by one, in random fashion, to impairment in some of the numerous genetic functions that govern the balance between protein oxidation and protein degradation. If so, validation of the concept will be difficult, if not impossible, because the combination of genetic defects that dictate the amount of oxidized protein in one individual may be different from those that determine the same amount in another individual. For example, mutations in one or more of the many genes that govern the concentration and activity of the proteases that degrade oxidized protein could be phenotypically indistinguishable from a variety of mutations that affect the rate of active oxygen generation or the amounts of scavenger enzymes and anti-oxidant metabolites that collectively determine the rate of protein oxidation.

But whatever the mechanism, the results of the studies with the gerbil brain indicate that the accumulation of oxidized proteins may be involved in the age-related loss of some physiological functions. The demonstration that chronic PBN treatment can restore some of these functions is reason for hope that a pharmacological intervention may be found to ameliorate age-related disorders.

\section{REFERENCES AND NOTES}

1. D. Harmon, J. Gerontol. 11, 298 (1956)

2. E. R. Stadtman and C. N. Oliver, J. Biol. Chem. 266, 2005 (1991)

3. B. A. Ames, M. K. Shingenaga, E.-M. Park, in Oxidation Damage and Repair: Chemical, Biological and Medical Aspects, K. J. A. Davies, Ed. (Pergamon, Elmsford, NY, 1991), pp. 181-187.

4. M. Rothstein, in Molecular Biology of Aging, A. D. Woodhead, A. D. Blackett, A. Hollaender, Eds. (Plenum, New York, 1985), pp. 193-204.

5. C. N. Oliver, R. L. Levine, E. R. Stadtman, in Metabolic Interconversion of Enzymes, $\mathrm{H}$. Holzer, Ed. (Springer-Verlag, Berlin, 1981), pp. 259-268.

6. R. L. Levine, C. N. Oliver, R. M. Fulks, E. R. Stadtman, Proc. Natl. Acad. Sci. U.S.A. 78, 2120 (1981).

7. R. M. Fulks and E. R. Stadtman, Biochim. Biophys. Acta 843, 214 (1985)

8. L. Fucci, C. N. Oliver, M. J. Coon, E. R. Stadtman, Proc. Natl. Acad. Sci. U.S.A. 80, 1521 (1983)

9. E. R. Stadtman, Free Radical Biol. Med. 9, 315 (1990).

10. R. L. Levine, J. Biol. Chem. 258, 11828 (1983)

11. J. M. Farber and R. L. Levine, ibid. 261, 4574 (1986).

12. I. Climent, L. Tsai, R. L. Levine, Anal. Biochem. 182, 226 (1989)

13. E. R. Stadtman and M. E. Wittenberger, Arch. Biochem. Biophys. 239, 379 (1985)

14. R. J. Almassy, C. A. Janson, R. Hamlin, N.-H. Xuong, D. Eisenberg, Nature 323, 304 (1986)

15. J. A. Sahakian, B. D. Shames, R. L. Levine, FASEB J. 5, A1177 (1991).

16. A. J. Swallow, in Radiation Chemistry of Organic Compounds, A. J. Swallow, Ed. (Pergamon, New York, 1960), pp. 211-224.

17. K. J. A. Davies, J. Biol. Chem. 262, 9895 (1987).

18. B. S. Berlett, O. H. M. Omar, J. A. Sahakian, R. L. Levine, E. R. Stadtman, FASEB J. 5, A1524 (1991).

19. H. Schuessier and K. Schilling, Int. J. Radiat. Biol. 45, 267 (1984).

20. W. M. Garrison, M. E. Jayko, W. Bennett, Radiat. Res. 16, 267 (1984)

21. J. M. Farber and R. L. Levine, Fed. Proc. 41, 865 (abstr. 3482) (1982).

22. A. J. Rivett, Arch. Biochem. Biophys. 243, 624 (1985).
23. K. J. A. Davies, S. W. Lin, R. E. Pacifici, J. Biol. Chem. 262, 9914 (1987).

24. A. J. Rivett, ibid. 260, 300 (1985); ibid., p. 12600 ; R. E. Pacifici, D. C. Salo, K. J. A. Davies, Free Radical Biol. Med. 7, 521 (1989).

25. K. J. A. Davies and S. W. Lin, Free Radical Biol. Med. 5, 217 (1988); O. Marcillat, Y. Zhang, S. W. Lin, K. J. A. Davies, Biochem. J. 254, 677 (1988); K. J. A. Davies and A. L. Goldberg, J. Biol. Chem. 262, 8227 (1987)

26. K. J. A. Davies, in Cellular and Molecular Aspects of Aging: The Red Cell As a Model, J. W. Eaton, D. K. Konzen, J. G. White, Eds. (Liss, New York 1984), pp. 15-24.

27. H. Gershon and D. Gershon, Nature 227, 1214 (1970); C. N. Oliver, R. L. Levine, E. R. Stadtman, J. Am. Geriatr. Soc. 35, 947 (1987).

28. E. R. Stadtman, Trends Biochem. Sci. 11, 11 (1986)

29. R. L. Levine et al., Methods Enzymol. 186, 464 (1990).

30. C. N. Oliver, B.-W. Ahn, E. J. Moerman, S. Goldstein, E. R. Stadtman, J. Biol. Chem. 262, 5488 (1987).

31. C. D. Smith et al., Proc. Natl. Acad. Sci. U.S.A. 88 10540 (1991).

32. D. Garland, P. Russell, J. S. Zigler, in Oxygeep Radicals in Biology and Medicine, M. G. Simic, K. S. Taylor, J. F. Ward, C. von Sonntag, Eds. (PR num, New York, 1988), pp. 347-353.

33. P. E. Starke-Reed and C. N. Oliver, Arch. Bid chem. Biophys. 275, 559 (1989).

34. J. M. Carney et al., Proc. Natl. Acad. Sci. U.S.A. 88, 3633 (1991).

35. C. N. Oliver et al., ibid. 87, 5144 (1990)

36. In this test, the gerbils are placed in a octagonal chamber, each side of which is connected to dead-ended tunnel. One by one, the gerbils ex plore each of the eight tunnels. An error is score if a gerbil reenters an arm that it has alreagy explored before it has explored all eight arms the maze. In this test, young gerbils made on the average 4.1 errors, whereas old gerbils made $9 \Phi$ errors; however, after 14 days of PBN treatmeio the old gerbils made only 4.2 errors (34).

37. P. E. Starke-Reed, C. N. Oliver, E. R. Stadtma FASEB J. 1, 36 (1987)

38. J. J. Harding, Adv. Protein Chem. 37, 247 (1985) A. Cerami and M. J. C. Crabb, Trends Pharmacer. Sci. 7, 271 (1986); A. Cerami, H. Vlassara, Brownlee, J. Cell. Biochem. 30, 111 (1986).

39. S. P. Wolff and R. T. Dean, Biochem. J. 245, 28 (1987).

40. V. M. Monnier, J. Gerontol. Biol. Sci. 45, B1 (1990); A. Cerami, H. Vlassara, M. Brownlee, Seg. Am. 256, 90 (1987).

41. E. Schauenstein and H. Esterbauer, in Submole ular Biology of Cancer, Ciba Foundation Series (Excerpta Medica Elsevier, Amsterdam, 1979) pp. 225-244; A. Benedetti, M. Comporti, H. Esterbauer, Biochim. Biophys. Acta 620, 281 (1980)

42. H. Esterbauer, H. Zollner, N. Schlotz, Z. Naturforsch. Teil C 30, 466 (1975).

43. K. Uchida and E. R. Stadtman, Proc. Natl. Acad. Sci. U.S.A. 89, 4544 (1992).

44. K. Uchida, L. Szweda, E. R. Stadtman, unpublished data.

45. A. Amici, R. L. Levine, L. Tsai, E. R. Stadtman, J. Biol. Chem. 264, 3341 (1989); J. M. Creeth, B. Cooper, A. S. R. Donald, J. R. Clamp, Biochem. J. 211, 323 (1983)

46. M. J. Poston, Fed. Proc. 46, 1979 (abstr. 315) (1988).

47. B. S. Berlett, D. G. Miller, L. Szweda, E. R Stadtman, unpublished data.

48. K. J. A. Davies, J. Biol. Chem. 262, 9902 (1987) 